\title{
Genetic diversity and relationships among accessions of five crested wheatgrass species (Poaceae: Agropyron) based on gliadin analysis
}

\author{
S.Y. Chen, X. Ma, X.Q. Zhang, L.K. Huang and J.N. Zhou \\ Key Laboratory of Grassland Science, Sichuan Province, \\ Department of Grassland Science, Animal Science and Technology College, \\ Sichuan Agricultural University, Yaan, Sichuan, China \\ Corresponding author: X.Q. Zhang \\ E-mail: zhangxq@sicau.edu.cn
}

Genet. Mol. Res. 12 (4): 5704-5713 (2013)

Received December 6, 2012

Accepted March 18, 2012

Published November 18, 2013

DOI http://dx.doi.org/10.4238/2013.November.18.19

\begin{abstract}
Agropyron Gaertn. is the most important genus in Triticeae (Poaceae), which includes many forage grasses with high economic value. The genetic diversity and relationships of 36 accessions from five crested wheatgrass species were analyzed by gliadin markers. A total of 54 product bands were detected after acid polyacrylamide gel electrophoresis (A-PAGE), of which $100 \%$ were polymorphic. The genetic similarity coefficient based on Nei-Li's method ranged from 0.065 to 0.755 with an average of 0.451 . The Shannon diversity information index showed that there was a high level of genetic diversity among the accessions. An unweighted pair group method with arithmetic average (UPGMA) dendrogram was constructed based on the Nei-Li's genetic similarity coefficients, which showed the phylogenetic relationships among accessions of different species. Analysis of molecular variance (AMOVA) showed that the proportion of variance explained by inter- and intraspecific variance was 9.34 and $90.66 \%$, respectively, which revealed that the genetic variations within species were higher than the variations among species. Based
\end{abstract}


on pairwise genetic distances $\left(\Phi_{\mathrm{ST}}\right)$ among species, the cluster analysis indicated that $A$. mongolicum had a low-affinity relationship with other species, while $A$. fragile showed a close relationship with $A$. cristatum ssp pectinatum. Finally, the implications of the results for the taxonomy of Agropyron were discussed.

Key words: Agropyron Gaertn.; Genetic diversity; Gliadin; Phylogenetic relationship

\section{INTRODUCTION}

Agropyron Gaertn., one of the most important perennial genera in Triticeae (Poaceae), encompasses 10-15 species, which are commonly called the crested wheatgrass complex, and is composed of a series of diploid, tetraploid, and hexaploid species containing the basic $\mathrm{P}$ genome (Dewey, 1984; Asay and Jensen, 1996). Agropyron species are native to Europe and Asia, especially in the low temperature Altiplano and Sandlot regions in Eurasia, and some species have also been introduced and widely cultivated in North America (Johnson, 1986; Clayton et al., 2006). Most Agropyron species are excellent sources of forage and habitat for livestock and wildlife, and they are also valued for weed control, habitat use, soil stabilization, and watershed management (Wang, 2011). In addition, some Agropyron species possess many excellent genes that make them resistant to abiotic stress and major diseases; these genes can be transferred to cultivated cereal crops, including wheat (Triticum aestivum L.), barley (Hordeum vulgare L.), and rye (Secale cereale L.), to develop new breeding materials, and they play an important role in the genetic improvement of cereal crops (Sharma and Gill, 1983; Dong et al., 1992; Wu et al., 2006).

The taxonomy of Agropyron underwent a major change and has been the object of considerable controversy. Agropyron used to be the largest genus in Triticeae, consisting of approximately 100 species that occur worldwide and have the characteristic of a single spikelet per node (Sakamoto, 1964). More recently, new taxonomic revisions have been proposed that are based on genomic or biological relationships as well as plant morphology. These revisions proposed that Agropyron should be restricted to species of the crested wheatgrass complex, a polyploid series based on the P genome (Dewey, 1984; Yen et al., 2005).

Traditionally, the delimitation of the crested wheatgrass complex mainly depended on the spike morphology, which varied in a continuous fashion from broad, pubescent, pectinate spikes to narrow, linear, glabrous spikes (Dewey and Asay, 1982). In the complex, A. cristatum (L.) Gaertn. and A. fragile (Roth) P. Candargy are the most used and widely distributed species, and they are commercially important. A. cristatum has short broad spikes that taper at the top, small seeds, and short stature; compared to A. cristatum, A. fragile has finer leaves and stems and narrower and awnless glumes and lemmas, and the spikelets are more ascending, giving the spike a narrow, oblong, subcylindrical shape (Clayton et al., 2006). Similarly, $A$. imbricatum (MB) Roem et Schult and A. pectinatum Roem et Schult are morphologically very similar to each other and to A. cristatum (L.) Gaertn.; they are differentiated by the level of pubescence and the spacing between spikelets. Tzvelev (1976) reclassified them as subspecies or varieties of A. cristatum, namely A. cristatum ssp imbricatum (Roem. \& Schult.) Beck and A. cristatum ssp pectinatum (M. Bieb.). The cytology data indicated that these three species 
differed in the absence or presence of B chromosomes and the position of satellites (Asghari et al., 2007). Moreover, A. mongolicum Keng, which is indigenous to China, is distinguished from $A$. cristatum by its narrow linear spikes. It was also postulated that $A$. fragile was an autopolyploid of A. mongolicum (Asay et al., 1992). However, the taxonomy is still controversial and difficult because the morphological characteristics that are used to distinguish its taxa are at least partially under environmental control and may not reflect their genetic basis (Sun and $\mathrm{Li}, 2006$ ). Furthermore, the complex is known for its morphological variability, but little is known about the genetic basis and systematic relationships, especially at the biochemical and molecular levels.

Gliadins, the important proportions of storage protein in the endosperm of Triticeae species, are encoded by highly conserved multigenic families, and differences in copy number result in gliadin polymorphisms (Shewry et al., 1999). The great variability of these proteins, which is a consequence of their neutral nature at the evolutionary level, can substantially contribute to the analysis of evolutionary forces that cause genetic variation and differentiation (Alvarez et al., 2006). Despite having fewer detectable loci than DNA molecular markers, gliadin markers still have great application potential in the identification of genotypes and characterization of genetic relationships between plant germplasms because of their simplicity, speed, and high repeatability (Ma et al., 2012). Hitherto, gliadin has been used as a powerful tool in Apropyron and other Triticeae species to reveal genetic diversity and population differentiation and to elucidate phylogenetic relationships and taxonomic problems (Che and Li, 2007; Özbek et al., 2011). The objectives of this study were therefore to detect genetic diversity and examine inter- or intraspecific systematic relationships among the Agropyron accessions.

\section{MATERIAL AND METHODS}

\section{Plant materials}

A total of 36 Agropyron accessions belonging to A. mongolicum, A. cristatum, A. cristatum ssp imbricatum, A. cristatum ssp pectinatum, and A. fragile were used in this study (Table 1). All of the seeds were obtained from the United States Department of Agriculture Agricultural Research Service (USDA-ARS), Regional Plant Introduction Station, Pullman, Washington, USA.

\section{Gliadin extraction and electrophoresis}

Twenty seeds of each accession were randomly selected and crushed into fine powders for the gliadin extraction. The gliadin was extracted with a solution of $25 \%$ 2-chlorohydrin $(\mathrm{v} / \mathrm{v})$ and $0.05 \%$ methyl green $(\mathrm{w} / \mathrm{v})$, and it was fractionated by standard acid polyacrylamide gel electrophoresis (A-PAGE) according to the procedure of Draper (1987). The gel concentration was $10 \%(\mathrm{w} / \mathrm{v})$, and the cross linker was $3.3 \%(\mathrm{w} / \mathrm{w})$. Electrophoresis was carried out at $500 \mathrm{~V}$ for $3 \mathrm{~h}$ at a constant temperature of $15^{\circ} \mathrm{C}$ in $\mathrm{pH} 3.1$ electrophoresis buffer. After electrophoresis, the gel was fixed in 10\% trichloroacetic acid (TCA) (w/v) and stained with $1 \%$ Coomassie brilliant blue R-250 (w/v). Destaining was carried out with 7\% acetic acid and tap water (v/v). Moreover, the Canadian wheat cultivar Marquis (Triticum aestivum 'Marquis') was taken as the standard for recording the band patterns. 
Table 1. Agropyron species used in the study.

\begin{tabular}{|c|c|c|c|}
\hline No. & Accessions No. & Species (Abbreviation) & Geographic origins \\
\hline 1 & PI499393 & A. mongolicum $(A . m)$ & Nei Monggol, China \\
\hline 2 & PI531543 & A. mongolicum $(A . m)$ & Nei Monggol, China \\
\hline 3 & PI598482 & A. mongolicum $(A, m)$ & China \\
\hline 4 & PI598460 & A. mongolicum $(A . m)$ & China \\
\hline 5 & PI564856 & A. cristatum (A. c) & Nei Monggol, China \\
\hline 6 & PI499566 & A. cristatum $(A . c)$ & Xinjiang, China \\
\hline 7 & PI499381 & A. cristatum (A. c) & Nei Monggol, China \\
\hline 8 & w613146 & A. cristatum (A. c) & Xinjiang, China \\
\hline 9 & PI401026 & A. cristatum subsp. pectinatum (A. c. p) & Kars, Turkey \\
\hline 10 & PI564882 & A. cristatum var. pectinatum (A. c. p) & Kazakhstan \\
\hline 11 & PI564884 & A. cristatum var. pectinatum (A. c. p) & Kazakhstan \\
\hline 12 & PI370649 & A. cristatum subsp. pectinatum (A. c.p) & Russian Federation \\
\hline 13 & PI370653 & A. cristatum subsp. pectinatum (A. c. p) & Novosibirsk region, Russian Federation \\
\hline 14 & PI370650 & A. cristatum subsp. pectinatum (A. c. p) & Russian Federation \\
\hline 15 & PI273734 & A. cristatum var. pectinatum (A. c. p) & Voronezh, Russian Federation \\
\hline 16 & PI494617 & A. cristatum var. pectinatum (A. c. p) & Constanta, Romania \\
\hline 17 & PI547323 & A. cristatum var. pectinatum (A. c.p) & Russian Federation \\
\hline 18 & PI326204 & A. cristatum subsp. pectinatum (A. c. p) & Kustanai region, Kazakhstan \\
\hline 19 & PI401027 & A. cristatum subsp. pectinatum (A. c.p) & Sakarya, Turkey \\
\hline 20 & PI401013 & A. cristatum var. imbricatum (A. c. $i)$ & Turkey \\
\hline 21 & PI401012 & A. cristatum var. imbricatum (A. c. $i)$ & Orenburg region, Turkey \\
\hline 22 & PI314605 & A. cristatum var. imbricatum (A. c. $i)$ & Alma Ata, Kazakhstan \\
\hline 23 & PI229574 & A. cristatum var. imbricatum (A. c. $i)$ & Azerbaijan, Iran \\
\hline 24 & PI401011 & A. cristatum var. imbricatum (A. c. $i)$ & Rostov region, Turkey \\
\hline 25 & PI285205 & A. cristatum var. imbricatum (A. c. i) & Russian Federation \\
\hline 26 & PI401028 & A. fragile $(A . f)$ & Saratov region, Turkey \\
\hline 27 & PI326206 & A. fragile $(A . f)$ & Aktyubinsk region, Kazakhstan \\
\hline 28 & PI108434 & A. fragile $(A . f)$ & Kazakhstan \\
\hline 29 & PI314606 & A. fragile $(A . f)$ & Alma Ata, Kazakhstan \\
\hline 30 & PI440494 & A. fragile $(A . f)$ & Dzhambul, Kazakhstan \\
\hline 31 & PI369522 & A. fragile $(A . f)$ & Siberia, Russian Federation \\
\hline 32 & PI273736 & A. fragile $(A . f)$ & Aktyubinsk, Kazakhstan \\
\hline 33 & PI370655 & A. fragile $(A . f)$ & Russian Federation \\
\hline 34 & PI276710 & A. fragile $(A . f)$ & Moscow, Russian Federation \\
\hline 35 & PI325184 & A. fragile $(A . f)$ & Stavropol, Russian Federation \\
\hline 36 & PI315366 & A. fragile $(A . f)$ & Stavropol, Russian Federation \\
\hline
\end{tabular}

\section{Data analysis}

The gliadin bands were scored manually for their presence (1) or absence (0) to construct the data matrix. The Nei-Li's genetic similarity (GS) coefficients were calculated, which were also used to compute principal coordinate analysis (PCoA) and construct the dendrogram using unweighted pair group method with arithmetic average (UPGMA) cluster analysis in the NTSYS 2.1 software (Gower, 1966; Nei and Li, 1979; Rohlf, 2000). The Shannon index was also applied to estimate the genetic diversity among the accessions as $H=-\Sigma \pi \mathrm{i} \ln \pi \mathrm{i}$, where $\pi \mathrm{i}$ is the frequency of a band in the group or subgroup. Additionally, to study the partition of inter- and intraspecific genetic variations of the gliadin, the analysis of molecular variance (AMOVA) was also conducted with the program WIN AMOVA 1.55 (Excoffier et al., 1992). The interspecific genetic distances were analyzed by the phi statistic $\left(\Phi_{\mathrm{ST}}\right)$. The number of permutations was set at 1000 for AMOVA and the significance test of the interspecific genetic distances.

\section{RESULTS}

\section{A-PAGE profile}

Up to 54 gliadin bands were detected among the 36 accessions of five crested wheat- 
grass species, of which $100 \%$ were polymorphic in the examined accessions. Forty-three (37 polymorphic bands), 44 (40 polymorphic bands), 51 (51 polymorphic bands), 49 (48 polymorphic bands), and 52 (52 polymorphic bands) bands were detected from $A$. mongolicum, A. cristatum, A. cristatum ssp pectinatum, A. cristatum ssp imbricatum, and A. fragile, respectively (Table 2). The largest number of bands was observed in A. cristatum ssp pectinatum, while the least was observed in A. mongolicum. The gliadin markers in the study could separate all of the accessions, and each accession had a unique band pattern.

\begin{tabular}{|c|c|c|c|}
\hline Species & Number of total bands & Polymorphic bands and rate & Shannon index $(H)$ \\
\hline A. mongolicum & 43 & $37(86.05 \%)$ & 0.3904 \\
\hline A. cristatum & 44 & $40(90.91 \%)$ & 0.4051 \\
\hline A. cristatum $\mathrm{ssp}$ imbricatum & 49 & $48(98.96 \%)$ & 0.4453 \\
\hline A. cristatum $\mathrm{ssp}$ pectinatum & 51 & $51(100 \%)$ & 0.4613 \\
\hline A. fragile & 52 & $52(100 \%)$ & 0.4639 \\
\hline Total & 56 & $56(100 \%)$ & 0.5240 \\
\hline
\end{tabular}

\section{GS coefficient and variability}

The GS coefficient among accessions based on Nei-Li's method ranged from 0.065 (PI531543, A. mongolicum and PI564856, A. cristatum) to 0.755 (PI370650, A. cristatum ssp pectinatum and PI285205, A. cristatum ssp imbricatum) with an average of 0.451 . At the intraspecific level, different accessions of each species revealed high similarity, and the GS value varied between 0.411 and 0.469 . The highest similarity value was 0.469 between $A$. cristatum ssp pectinatum and $A$. fragile, while the lowest value was 0.411 between $A$. mongolicum and A. cristatum ssp imbricatum. The Shannon diversity information index of all accessions was 0.5240 , and indices of A. mongolicum, A. cristatum, A. cristatum $\mathrm{ssp}$ imbricatum, A. cristatum ssp pectinatum, and $A$. fragile were $0.3904,0.4051,0.4453,0.4613$, and 0.4639 , respectively (Table 2 ). This finding showed that there was a high level of genetic diversity among the accessions, and the genetic variations within the species were higher than the variations among the species of the complex.

\section{Cluster and PCoA analysis}

The dendrogram constructed from Nei-Li's genetic similarity coefficient with UPGMA analysis revealed several main clusters (Figure 1), which revealed the genetic relationships among the Agropyron species at the inter- and intraspecific levels. Cluster I contains one accession of $A$. cristatum from China and one accession of $A$. cristatum ssp imbricatum from Turkey. In cluster II, there was only one accession of $A$. cristatum ssp imbricatum from Iran. Cluster III contained two accessions from the same region of the Russian Federation, A. cristatum ssp pectinatum and A. fragile. Finally, cluster IV included the remainder of the accessions, which could then be further divided into five subgroups. Subgroup IV-1 consisted of three $A$. mongolicum accessions from China. Subgroup IV-2 contained nine accessions belonging to the five species. Subgroup IV-3 included 13 accessions from the four species, except $A$. mongolicum. Subgroup IV-4 was composed of three A. fragile accessions and one A. cristatum ssp pectinatum accession, all of which were from Kazakhstan. Finally, two other $A$. fragile accessions from the Russian Federation were clustered in subgroup IV-5. 


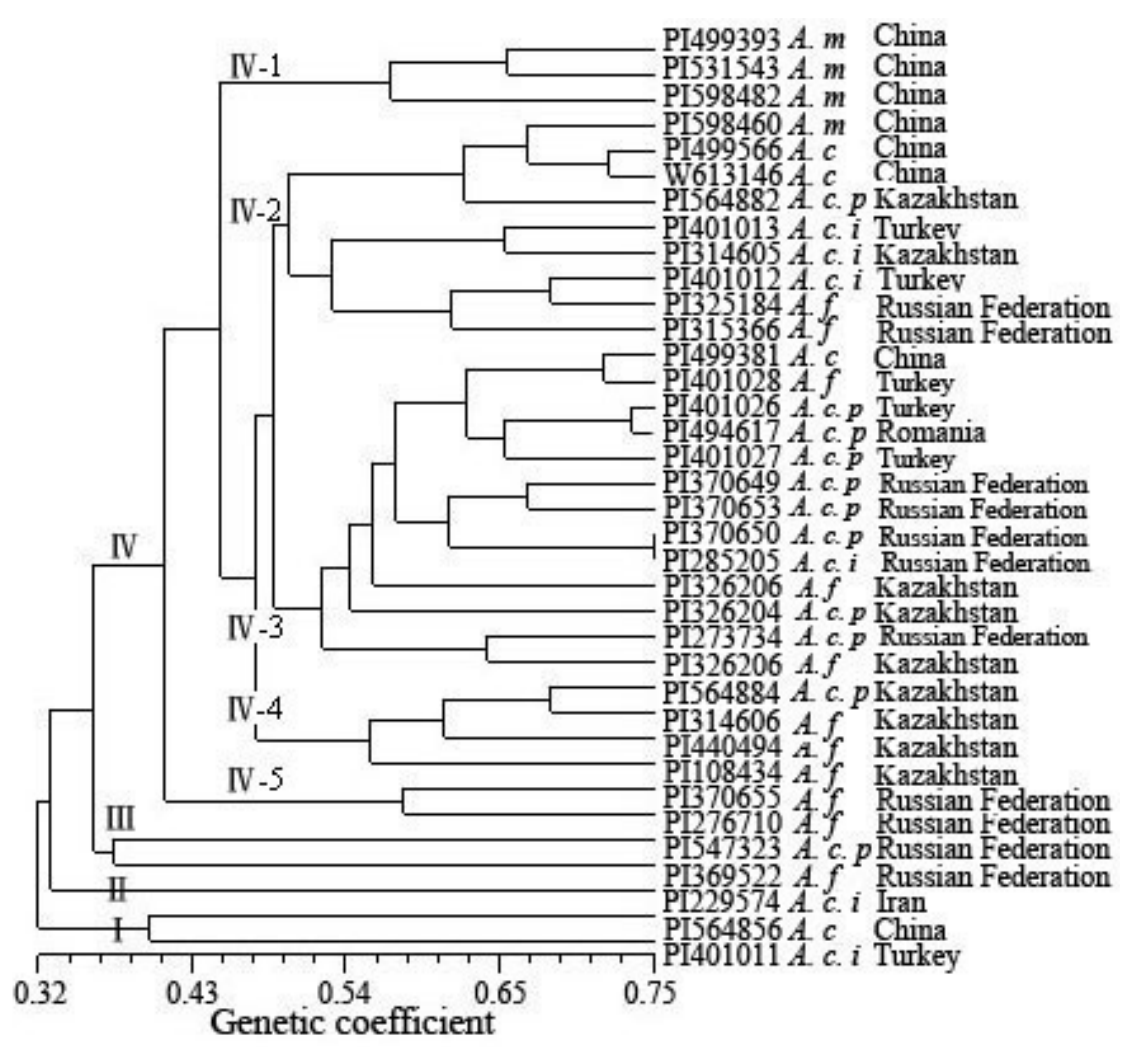

Figure 1. UPGMA dendrogram generated by Nei-Li's genetic similarity coefficients based on gliadin analysis.

PCoA was performed based on the genetic similarity matrix to better understand relationships among the accessions of different species (Figure 2). The three most informative principal coordinate components accounted for $56.76 \%$ of the variations, of which Principal Coordinate 1, 2, and 3 explained 47.37, 5.01, and 4.38\% of the variation, respectively. The PCoA also revealed groupings that were similar to those from the UPGMA cluster dendrogram. The PCoA results indicated that there was a clear separation between A. mongolicum and other Agropyron species (Figure 2).

\section{AMOVA analysis}

AMOVA analysis revealed that molecular variation accounted for 9.34 and $90.66 \%$ of the variation among and within species, respectively. Then, pairwise $\Phi_{\mathrm{ST}}$ values $\left(\Phi_{\mathrm{ST}}\right.$ distances) were obtained based on the AMOVA analysis, which indicated the genetic distances among the species. Table 3 showed that the distance between A. cristatum ssp pectinatum and A. fragile was the lowest (0.0250), and the distance between A. mongolicum and A. cristatum ssp imbricatum was the highest (0.2106). The UPGMA dendrogram (Figure 3) based on pairwise $\Phi_{\mathrm{ST}}$ distances clearly showed the relationships among the five species, which were congruent with the previous cluster analysis of 36 accessions based on Nei-Li's GS coefficients. 


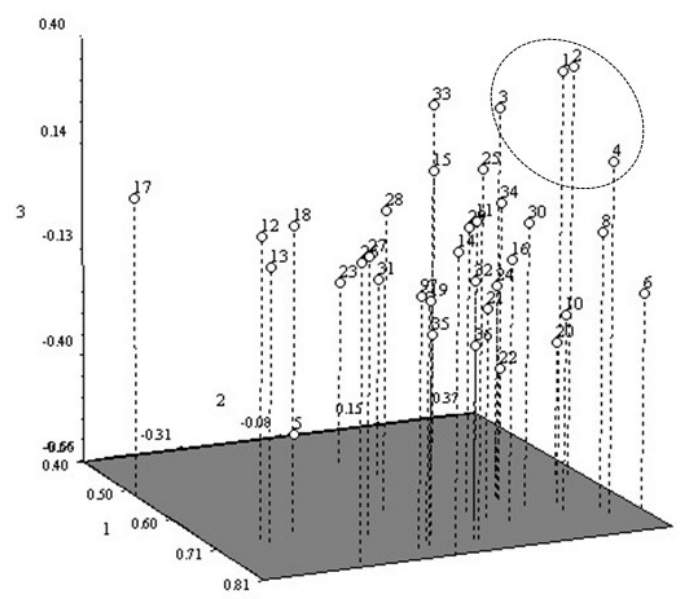

Figure 2. Relationships among the accessions of five Agropyron species visualized by principal coordinate analysis (PCoA) of gliadin-based genetic similarities.

Table 3. Pairwise $\Phi_{\mathrm{ST}}$ distance of five Agropyron species.

\begin{tabular}{|c|c|c|c|c|c|}
\hline Species & A. mongolicum & A. cristatum & A. cristatum $\mathrm{ssp}$ imbricatum & A. cristatum $\operatorname{ssp}$ pectinatum & A. fragile \\
\hline A. mongolicum & 0.0000 & & & & \\
\hline A. cristatum & 0.1859 & 0.0000 & & & \\
\hline A. cristatum $\mathrm{ssp}$ imbricatum & 0.2106 & 0.1390 & 0.0000 & & \\
\hline A. cristatum $\mathrm{ssp}$ pectinatum & 0.1611 & 0.0400 & 0.0619 & 0.0000 & \\
\hline A. fragile & 0.1537 & 0.0817 & 0.0425 & 0.0250 & 0.0000 \\
\hline
\end{tabular}
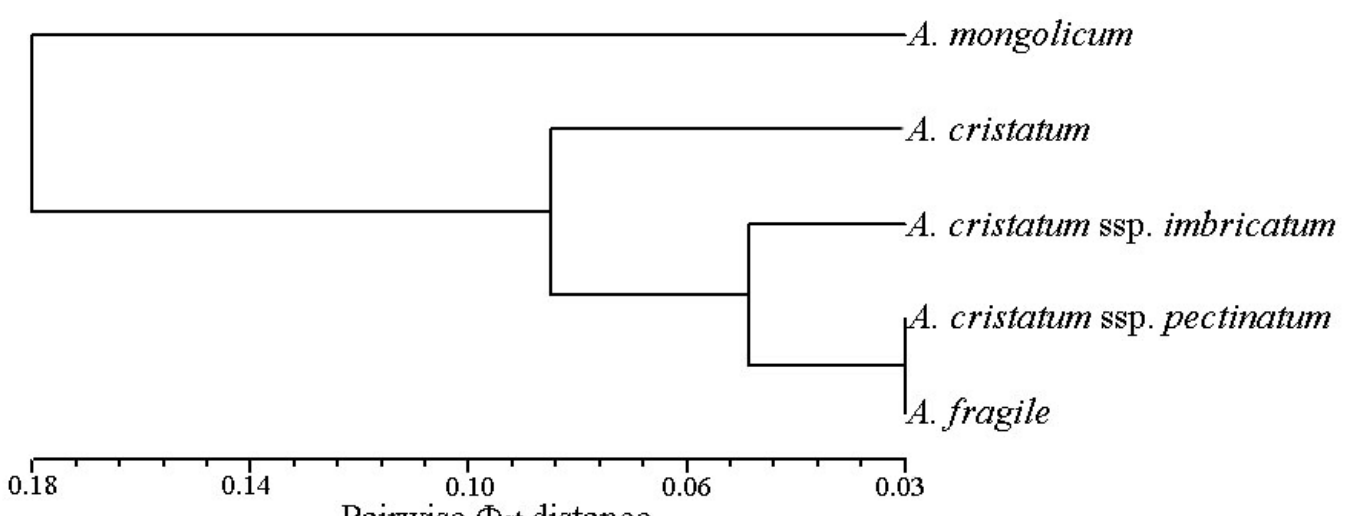

\section{Pairwise $\Phi$ st distance}

Figure 3. UPGMA clustering of five Agropyron species based on pairwise $\Phi_{\text {ST }}$ distances.

\section{DISCUSSION}

In the present study, substantial genetic diversity was revealed among accessions of different species, and the gliadin marker was also proved as a powerful tool in cultivar or acces- 
sion identification. Che and $\mathrm{Li}$ (2007) stated that a total of 81 gliadin bands were detected from 40 populations of $A$. mongolicum that was indigenous to Northern China, which showed that populations from similar eco-geographical situations could be clustered together. Furthermore, gliadin was widely applied in two other important wheatgrass species, Elymus nutans and E. sibiricus, which revealed considerable genetic variation and distinct geographical divergence among the accessions (Miao et al., 2011; Ma et al., 2012). Therefore, they also indicated that gliadin was a rapid, simple, and efficient marker system for genetic research of Triticeae species.

The results of the cluster analysis showed that most of the different accessions in a single species and the species from the same area were clustered together. Therefore, the cluster analysis based on gliadin was closely related to the geographical origins. However, a few accessions (for instance, cluster II) could not be clustered in any group and presented specificities, which might have resulted from various selection forces that tended to produce genetic heterogeneity in different small niches caused by different ecological factors. Nevo et al. (1997) analyzed the protein variation in natural populations both at macro- and microgeographical scales and concluded that the patterns of protein diversity were often related to ecological factors. Unfortunately, we did not detect any clear separation between different species or subspecies, which indicated that they had similar genetic bases and a great deal of genetic diversity among species.

In this study, A. mongolicum and $A$. cristatum had relatively low diversity index values, while $A$. fragile and $A$. cristatum ssp pectinatum had relatively high values. This finding might be associated with the geographical origins of the accessions and their complicated habitats because the accessions of the 1st two species were mainly from China, and the last 2 species in this study were from a wide geographical area. The role of ecological factors has been emphasized in determining the extent and distribution of genetic diversity in crop wild relatives and Triticeae species (Nevo, 1998; Chen et al., 2009). Moreover, significant correlation was also found between genetic diversity and sample size; therefore, this result might also be related to the sample size (Godt et al., 1996). Additionally, the results of AMOVA and Shannon index both revealed that the genetic variations within the species were higher than the variations among the species of the complex. Mellish et al. (2002) also reported that the majority of the AFLP variance (88\%) was found within the Agropyron species population, which may be because they are all outcrossing species.

Hsiao et al. (1986) described that although A. mongolicum and A. cristatum had similar genome lengths, there were some structural rearrangements between their P genomes, which were called the $\mathrm{P}_{\mathrm{c}}$ and $\mathrm{P}_{\mathrm{m}}$ genome. Similarly, A. mongolicum was not closely related to $A$. cristatum and other species in the study. The pairwise $\Phi_{\text {ST }}$ distances indicated that $A$. mongolicum showed a relatively low affinity relationship with other species, which was also similar to the results of a previous study that was based on amplified fragment length polymorphism (AFLP) markers (Mellish et al., 2002). Nevertheless, A. cristatum $\operatorname{ssp}$ pectinatum showed a close relationship with $A$. fragile and not with $A$. cristatum or with $A$. cristatum ssp imbricatum, which could have resulted because of the overlap in the geographical distribution of the two species and because they possess similar habitats.

In conclusion, this study indicated that gliadin was a rapid, simple, and efficient marker for genetic analysis of Agropyron species. Then, on the basis of the gliadin analysis, substantial genetic diversity was detected among accessions of different species. It also showed a clear division between $A$. mongolicum and the 4 other species and a certain degree 
of separation between $A$. cristatum and $A$. fragile. Nonetheless, it seemed that these results did not support the classification of $A$. cristatum ssp imbricatum and $A$. cristatum ssp pectinatum as subspecies of $A$. cristatum. Therefore, in order to draw convincing conclusions about the systematic relationships among the Agropyron species, further research needs to be conducted with more accessions from each species and additional analysis methods.

\section{ACKNOWLEDGMENTS}

Research supported by the National Natural Science Funds of China (\#31072077 and \#31101763) and the earmarked fund for Modern Agro-Industry Technology Research System (\#CARS-35-05). The authors also thank the USDA for kindly supplying the seeds for the study.

\section{REFERENCES}

Alvarez JB, Broccoli A and Martin LM (2006). Variability and genetic diversity for gliadins in natural populations of Hordeum chilense Roem. et Schult. Genet. Resour. Crop Evol. 53: 1419-1425.

Asay KH and Jensen KB (1996). Wheatgrasses. In: Cool-Season Forage Grasses (Moser LE, Buxton DR and Casler MD, eds.). ASA-CSSA-SSSA, Madison, 691-724.

Asay KH, Jensen KB, Hsiao C and Dewey DR (1992). Probable origin of standard crested wheatgrass, Agropyron desertorum Fisch ex Link, Schultes. Can. J. Plant Sci. 72: 763-772.

Asghari A, Agayev Y and Fathi SA (2007). Karyological study of four species of wheat grass (Agropyron sp.). Pak. J. Biol. Sci. 10: 1093-1097.

Che YH and Li LH (2007). Genetic diversity of prolamines in Agropyron mongolicum Keng indigenous to northern China. Genet. Resour. Crop Evol. 54: 1145-1151.

Chen SY, Ma X, Zhang XQ and Chen ZH (2009). Genetic variation and geographical divergence in Elymus nutans (Poaceae: Triticeae) from west China. Biochem. Syst. Ecol. 37: 722.

Clayton WD, Vorontsova MS, Harman KT and Williamson H (2006). GrassBase - The Online World Grass Flora. Available at [http://www.kew.org/data/grasses-db.html]. Accessed November 08, 2006.

Dewey DR (1984). The Genomic System of Classification as a Guide to Intergeneric Hybridization with the Perennial Triticeae. In: Gene Manipulation in Plant Improvement (Gustafson JP, ed.). Plenum Publishing Corp, New York, 209-279.

Dewey DR and Asay KH (1982). Cytogenetic and taxonomic relationships among three diploid crested wheatgrasses. Crop Sci. 22: 645-650.

Dong YS, Zhou RH, Xu SJ, Cauderon Y, et al. (1992). Desirable characteristics in perennial Triticeae collected in China for wheat improvement. Hereditas 116: 175-178.

Draper SR (1987). ISTA Variety Committee - Report of the working group for biochemical tests for cultivar identification 1983-1986. Seed Sci. Tech. 15: 431-434.

Excoffier L, Smouse PE and Quattro JM (1992). Analysis of molecular variance inferred from metric distances among DNA haplotypes: application to human mitochondrial DNA restriction data. Genetics 131: 479-491.

Godt MJW, Johnson BR and Hamrick JL (1996). Genetic diversity and population size in four rare southern appalachian plant species. Conserv. Biol. 10: 796-805.

Gower JC (1966). Some distance properties of latent root and vector methods used in multivariate analysis. Biometrika 53: 325-338.

Hsiao C, Wang RRC and Dewey DR (1986). Karyotype analysis and genome relationships of 22 diploid species in the tribe Triticeae. Can. J. Genet. Cytol. 28: 109-120.

Johnson DA (1986). Seed and Seedling Relations of Crested Wheatgrass: A Review. In: Crested Wheatgrass: Its Values, Problems and Myths (Johnson KL, ed.). Proceedings of Symposium, Utah State University, Logan, 65-90.

Ma X, Chen SY, Zhang XQ, Bai SQ, et al. (2012). Assessment of worldwide genetic diversity of Siberian wild rye (Elymus sibiricus $\mathrm{L}$.) germplasm based on gliadin analysis. Molecules 17: 4424-4434.

Mellish A, Coulman B and Ferdinandez Y (2002). Genetic relationships among selected crested wheatgrass cultivars and species determined on the basis of AFLP markers. Crop Sci. 42: 1662-1668.

Miao JM, Zhang XQ, Chen SY, Ma X, et al. (2011). Gliadin analysis of Elymus nutans Griseb. from the Qinghai-Tibetan Plateau and Xinjiang, China. Grassland Sci. 57: 127-134. 
Nei M and Li WH (1979). Mathematical model for studying genetic variation in terms of restriction endonucleases. Proc. Natl. Acad. Sci. U. S. A. 76: 5269-5273.

Nevo E (1998). Genetic diversity in wild cereals: regional and local studies and their bearing on conservation ex situ and in situ. Genet. Resour. Crop Evol. 45: 355-370.

Nevo E, Apelbaum-Elkaher I, Garty J and Beiles A (1997). Natural selection causes microscale allozyme diversity in wild barley and a lichen at 'Evolution Caryon' Mt. Carmel, Israel. Heredity 78: 373-382.

Özbek Ö, Taşkın BG, Şan SK, Eser V, et al. (2011). Gliadin polymorphism in Turkish cultivated emmer wheat [Triticum turgidum L. ssp. dicoccon (Schrank) Thell.] landraces. Plant Syst. Evol. 296: 121-135.

Rohlf FJ (2000). NTSYSpc: Numerical Taxonomy and Multivariate Analysis System, Version 2.1 Exeter Software. Applied Biostatics Inc., New York.

Sakamoto S (1964). Cytogenetical problems in Agropyron hybrids. Seiken Jiho 16: 38-47.

Sharma HC and Gill BS (1983). Current status of wide hybridization in wheat. Euphytica 32: 17-31.

Shewry PR, Tatham AS and Halford NG (1999). The Prolamins of the Triticeae. In: Seed Proteins (Shewry PR and Casey R, eds.). Kluwer Academic Publishers, Dordrecht, 35-78.

Sun GL and Li W (2006). Molecular diversity of species of the Elymus trachycaulus complex and their relationships to non-North American taxa. Plant Syst. Evol. 256: 179-191.

Tzvelev NN (1976). Tribe 3. Triticeae Dum. In: Poaceae URSS Nauka Publishing House, St. Leningrad, 105-206.

Wang RRC (2011). Agropyron and Psathyrostachys. In: Wild Crop Relatives: Genomic and Breeding Resources (Kole C, ed.). Springer-Verlag, Berlin Heidelberg, 77-83.

Wu J, Yang X, Wang H, Li H, et al. (2006). The introgression of chromosome 6P specifying for increased numbers of florets and kernels from Agropyron cristatum into wheat. Theor. Appl. Genet. 114: 13-20.

Yen C, Yang JL and Yen Y (2005). Hitoshi Kihara, Áskell Löve and the modern genetic concept of the genera in the tribe Triticeae (Poaceae). Acta Phytotaxon. Sin. 43: 82-93. 